\section{CITES-does it offer wild species a future?}

The next meeting of the Convention on International Trade in Endangered Species of Wild Fauna and Flora (CITES) will be held at UNEP Headquarters in Nairobi in April 2000. Intended to save wild species from extinction by restricting and regulating the international trade in wildlife, CITES was signed in Washington DC in 1973 and it came into force 2 years later. Over the last quarter of a century it has proved to be the most high-profile and controversial of the international environmental treaties, attracting a great deal of media and public attention. At times the issue of disappearing species has seemed to serve as a lightning rod for more general concerns about the harm humans are doing to the natural world. CITES has become a battleground for competing responses to environmental problems and, in consequence, expectations have been placed on CITES that it has not always been able to fulfil. But whatever its wider symbolic importance, there are now real doubts about the ability of CITES to achieve its primary goal of saving species. These doubts are a response to a number of connected developments in wildlife conservation, which have picked up pace in the last decade.

Most centrally, there have been improvements in our understanding of the threats to wild species. This has raised questions about both the diagnosis and the prescription offered by CITES. The treaty assumes that the international commercial trade in wild species is the central threat to their continued existence. Indeed, it is the only threat it addresses. The solution that CITES offers boils down to a mixture of bans on international trade for the most endangered species, and regulation of the trade in less seriously threatened species. Part of the weakness of CITES is that it has not always been successful in enforcing its bans and regulations. Illegal trade has sometimes continued and even where trade is legal it has not been effectively regulated by CITES. A more serious weakness is that, for many species, international commercial trade may not be the primary or underlying threat. It has come to be recognized that the loss of wildlife habitat, as humans convert it to agriculture and other uses, offers a greater threat to the survival of wildlife than any other factor. As a result, the remedies offered by CITES, premised on the assumption that trade is inevitably a threat to wildlife, are often inappropriate. Indeed, there is an argument that in some cases the 'solutions' supplied by CITES have actually exacerbated the problem. By restricting trade in wild species, and so limiting the benefits that humans can derive from them, CITES has actually reduced the incentive to maintain wildlife habitat, adding to the rate of decline.

The growing acknowledgement of the importance of habitat loss as a primary threat to wildlife has led some conservationists to suggest that the human use of wildlife, and commercial trade in particular, can actually be a positive force for conservation. For this school of thought, the key issue is whether or not the overall off-take of a species is sustainable in the long term, not the use to which the species is being put. In effect, this is to challenge the basic presumptions of CITES. It has also raised the ire of those who would oppose the use of wildlife on any grounds, even if it serves conservation ends. For this constituency, the commercial exploitation of wildlife is simply an inappropriate way to relate to nature. The debate about the effectiveness of CITES has picked up pace in recent years and there have been some shifts, albeit of a piecemeal kind, in the direction of pragmatism, in which the 'sustainable use' of species has been sanctioned. But there must be questions about how far CITES, as it is currently structured and implemented, can adapt itself to address the complexities of the conservation challenge.

A second, related development, has been the louder voice assumed by countries of the South in debates within CITES. For the original treaty was largely developed by conservationists from the North and reflected their conception of the problem. Southern African countries have been particularly prominent in promoting what they see as a new perspective on conservation, one that distances itself from the preservationist approach that was its legacy from the colonial period. Southern Africans in particular often emphasize that if conservation is to be successful it must provide tangible benefits to those who live closest to the wildlife.

The third linked development has been an increasing emphasis on the social dimension of conservation. At the same time as the inherent limitations of CITES have become apparent, the need for a more sophisticated understanding of the complexity of the interactions between wildlife and human society has become more pressing. Because the two are so closely intertwined, a policy for wildlife is simultaneously a policy for human society, raising questions of justice and equity within human society. The popular notion of sustainable development was adopted at the United Nations Conference on Environment and Development in 1992 as an acknowledgement of the linkage between environmental and social concerns.

In their struggle to conserve species, conservationists 
appear to be learning that it is not enough to draw on the biological sciences and the study of population dynamics. They need major inputs from the social sciences as well because in most cases both the conservation problem and its solution are centred on people. However, there has been some reluctance to engage with these issues within CITES. The original Articles almost totally ignore the human element of conservation and its structure allows little flexibility in the face of uncertainty. There are only two ways in which CITES can deal with the situation where the fundamental threat to an endangered species is habitat loss and where its conservation status might be improved as a result of the economic incentives provided by a limited, controlled commercial trade. The first is to follow the Articles and prohibit commercial trade, irrespective of its consequences. The second is to cheat by listing the species on Appendix II despite the fact that it is endangered.

These three developments-better appreciation about the nature of threats to wildlife, the role of countries from the South in shifting the debate, and the greater emphasis on the social dimensions of conservation-have all combined to unsettle CITES. A fourth development, in part a consequence of the first three, has been the signing of the Convention on Biological Diversity. A broader and potentially more comprehensive treaty than CITES, and one that takes into account new information and trends in conservation, this poses a question about the institutional future of CITES.
The time is surely ripe for a critical assessment of CITES. Surprisingly, for all the controversy and media attention that has sometimes surrounded the Convention, it has been subject to little sustained analysis. Even amongst those who would embrace the concepts of human-centred conservation and sustainable use, there is room for significant debate about how it might be accommodated within this Convention.

As we approach the 11th Conference of the Parties to CITES, we feel that all those involved in the Convention, from the Parties and the Secretariat to academics and the NGO community, would benefit most if they found the time to step back and reconsider the nature of the conservation challenge, the way that CITES can best intervene and what must be done to make this possible. Unfortunately, we are most likely to see the usual polarized debate as to which list or 'Appendix' is most appropriate for the African elephant!

Jon Hutton

Africa Resources Trust, The World Conservation Monitoring Centre, 219 Huntingdon Road, Cambridge CB3 ODL, UK

(fax: + 44 (0)1223 277 136; e-mail: hutton@artint.force9.co.uk)

Barney Dickson

Holmsgarth, Blackheath, Wenhaston, Suffolk IP19 9ET, UK

(e-mail: bw.dickson@virgin.net)

Jon Hutton and Barney Dickson are editors of Endangered Species, Threatened Convention: The Past, Present and Future of CITES, which has just been published by Earthscan.

\section{A change of editor}

After 18 years as Editor of Oryx, the time has come for me to move on to new activities. I have enjoyed the role enormously and much of that enjoyment has been a result of the support I have received from a vast number of people: senior editors, editorial board members past and present, contributors, reviewers, colleagues at Fauna \& Flora International and staff at
Blackwell Science Ltd. I thank you all for your time, constructive feedback and encouragement. As I write, Fauna \& Flora International is in the process of appointing a new editor and I hope that he or she will find the job as rewarding as $I$ have done.

Jacqui Morris 